\title{
SOLID SELF MICROEMULSIFYING DRUG DELIVIRY SYSTEM: A REVIEW
}

\author{
Bhavna*, Aggarwal Geeta, HariKumar S L \\ Rayat and Bahra Institute of Phamacy, Sahauran, Kharar, District Mohali, Punjab, India-140104 \\ *Corresponding author's Phone No: 9569771167, E.mail: manikarnika21@gmail.com
}

\begin{abstract}
Oral route still remains the favorite route of drug administration in many diseases and till today it is the first way investigated in the development of new dosage forms. The major problem in oral drug formulations is low and erratic bioavailability, which mainly results from poor aqueous solubility. As a consequence of modern drug discovery techniques, there has been a steady increase in the number of new pharmacologically active lipophilic compounds that are poorly water soluble. It is a great chal lenge for pharmaceutical scientist to convert those molecules into orally administered formulation with sufficient bioavailability. Among the several approaches to improve oral bioavailability of these molecules, self-micron emulsifying drug delivery system (SMEDDS) is one of the approaches usually used to improve the bioavailability of lipophillic drugs. However, conventional SMEDDS are mostly prepared in a liquid form, which can have some disadvantages. Hence, solid SMEDDS (S-SMEDDS) prepared by solidification of liquid/semisolid self-micron emulsifying ingredients into powders, have gained popularity. This article gives an overview of the recent advances in the study of S-SMEDDS, especially the related solidification techniques and the development of solid self-micron emulsifying dosage forms. Finally, the existing problems and the possible future research directions in this field are pointed out. Thus S-SMEDDS could be used as an effective oral solid dosage form to improve the bioavailability of hydrophobic drugs.
\end{abstract}

Keywords: solid SMEDDS, self emulsification, solubility enhancement, bioavailability, lipophilic

\section{INTRODUCTION}

Oral route is the easiest and most convenient route for non invasive drug administration. Oral drug delivery systems being the most cost-effective have been leading the worldwide in the drug delivery market. Numerous potent lipophilic drugs exhibit low oral bioavailability due to their poor aqueous solubility properties. Efforts are ongoing to enhance the oral bioavailability of lipophilic drugs in order to increase their clinical efficacy. The most popular approach is the incorporation of the active lipophilic component into inert lipid vehicles, such as oils, surfactant dispersions, selfemulsifying formulations, emulsions and liposomes, with every formulation approach having its special advantages and limitations.

Efficacy of lipophilic drug is often hindered due to their poor aqueous solubility leading to low absorption after in vivo administration. A part of the administered dose is absorbed and reaches the pharmacological site of action and remainder causes toxicity and undesirable side effects due to unwanted bio-distribution. Enhancement in drug efficacy and lowering of drug toxicity could be achieved through encapsulation and delivery of the drug in lipid based delivery system.

The concept of drug delivery system has emerged to minimize the toxic side effects of drug, to broaden their application, to expand modes of their administration and to solve absorption problems. The twentieth century has witnessed a remarkable growth in drug development and the newly developed drugs are mostly lipophilic compound with poor aqueous solubility, which limits their efficacy and bioavailability. Solubilization, encapsulation, and delivery of these drugs using lipid based and biocompatible systems are likely to furnish better absorption, by way of lower dose, reduced frequency of administration, and improved therapeutic index.

Over recent years, much attention has been focused on lipid microemulsion formulations, with particular emphasis on liquid self-microemulsifying and self-emulsifying drug delivery systems (SEDDS) to improve the oral bioavailability of poorly water-soluble drugs ${ }^{1,2,3}$. However, these delivery systems had a few limitations, such as stability, the manufacturing methods, the interaction between the filling and the capsule shell, and the storage temperature ${ }^{4}$. When the product is kept at lower temperatures, there may be some precipitation of the active ingredient and/or the excipients. Therefore, the precipitated materials should be dissolved again when warmed to room temperature or the drug will not be present in solution or as a fine emulsion droplet ${ }^{3}$. Moreover, its efficiency is dependent upon a moist environment ${ }^{5}$.Thus solid self microemulsifying drug delivery system (SSMEDDS) should be carefully explored as a means of overcoming these problems.

\section{NEED OF S-SMEDDS}

S-SMEDDS, one of the lipid-based drug delivery systems prepared by the incorporation of liquid excipients into powders by solidification, is a promising drug delivery system for poorly water soluble compounds as it combines the advantages of liquid SMEDDS (solubility and bioavailability enhancement) with those of solid dosage forms (high stability with various dosage forms options ${ }^{6}{ }^{6,7}$. S-SMEDDS produce oil-in-water microemulsions with droplet sizes of less than $200 \mathrm{~nm}$ upon mild agitation in aqueous media (such as gastrointestinal fluids) ${ }^{7,8}$. These fine microemulsion droplets have the advantage of presenting the drug in a dissolved form with a large interfacial surface area for drug absorption, which results in an enhanced and more uniform and reproducible bioavailability 9 .

SMEDDS are usually, however, limited to liquid dosage forms, because many excipients used in SMEDDS are not solids at room temperature. Given the advantages of solid dosage forms, S-SMEDDS have been extensively exploited in recent years, as they frequently represent more effective alternatives to conventional liquid SMEDDS. From the perspective of dosage forms, S-SMEDDS mean solid dosage forms with self-emulsification properties. S-SMEDDS focus 
on the incorporation of liquid/semisolid self micron emulsifying ingredients into powders/nanoparticles by different solidification techniques (e.g. adsorptions to solid carriers, spray drying, melt extrusion, nanoparticles technology, and so on). Such powders/nanoparticles, which refer to self emulsifying nanoparticles ${ }^{10}$, dry emulsions/solid dispersions, are usually further processed into other solid SE dosage forms, or, alternatively, filled into capsules (i.e. self micro emulsifying capsules). Self micro emulsifying capsules also include those capsules into which liquid/semisolid SMEDDS are directly filled without any solidifying excipients. To some extent, S-SMEDDS are combinations of SMEDDS and solid dosage forms, so many properties of SSMEDDS (e.g. excipients selection, specificity, and characterization) are the sum of the corresponding properties of both SMEDDS and solid dosage forms. For instance, the characterizations of self micron emulsifying pellets contain not only the assessment of self-emulsification, but also friability, surface roughness, and so on. In the 1990s, SSMEDDS were usually in the form of self micron emulsifying capsules, self micron emulsifying solid dispersions and dry emulsions, but other solid self micron emulsifying dosage forms have emerged in recent years, such as self micron emulsifying pellets/tablets, self micron emulsifying microspheres/nanoparticles and self micron emulsifying suppositories/implants.

\section{ADVANTAGES OF S-SMEDDS ${ }^{12,13}$}

- Low production cost

- Convenience of process control

- High stability and reproducibility

- Better patient compliance

- Spontaneous formation

- Thermodynamic stability and

- Improved solubilization of bioactive materials

- More consistent temporal profiles of drug absorption

- less drug need to be used

- For many drugs taken by mouth

- Faster release rates and it improve the drug acceptance by consumers

- Selective drug targeting toward a specific absorption window in the GI tract and

- Drug protection from the hostile environment in the gut

- Thus, for lipophilic drug compounds that exhibit dissolution rate limited absorption

- These systems may offer an improvement in the rate and extent of absorption and result in more reproducible blood time profiles

- This may lower cost.

\section{S-SMEDDS OVERCOMING THE NEED OF LIQUID SMEDDS $^{14}$}

- $\quad$ S-SMEDDS form is more preferred than liquid SMEDDS form.

- $\quad$ S-SMEDDS (solid microemulsion preconcentrate) readily forms microemulsion when comes in contact with water.
- Need for outsourcing of soft gelatin capsule manufacturing at the early stage of drug product development may be avoided.

- S-SMEDDS remain solid at room temperature, yet maintains all the advantages of liquid SMEDDS.

- $\quad$ S-SMEDDS can be filled into hard gelatin capsules.

- $\quad$ S-SMEDDS is highly stable and reproducible than liquid SMEDDS.

- S-SMEDDS may even be incorporated into other solid dosage forms (e.g., fast dissolving tablets, films etc.

\section{ADVANTAGES OF S-SMEDDS OVER EMULSION:}

Microemulsions help in the improvement of drug bioavailability, protection against enzymatic hydrolysis and decrease toxicity. The only problem with microemulsion is poor palatability and moreover due to their water content, microemulsions cannot be encapsulated in soft and hard gelatin $^{11}$. Hence, there is a need for delivery of lipophillic drug in S-SMEDDS

\section{FORMULATION OF S-SMEDDS}

Formulation components of S-SMEDDS include

- Drug

- Oil

- Surfactants/ cosurfactants

- Co solvents

- Consistency builders

- Enzyme inhibitors

- Adsorbents/solidifying agents

The selection of oil, surfactant and co solvent is based on the solubility of the drug and preparation of the phase diagram.

\section{Selection of components for S-SMEDDS}

- The crucial challenges to any oral formulation design program is maintaining drug solubility within the gastrointestinal tract and, in particular, maximizing drug solubility within the primary absorptive site of the gut ${ }^{16}$.

- Lipid based formulations offer a potential platform for improving oral bioavailability of drugs especially those belonging to biopharmaceutical Classification System (BCS) class II and class IV.

Class II drugs are poorly water soluble drugs with high permeability but once they are dissolved; they absorbed over the gastro- intestinal membrane, and Class IV compounds are poorly soluble with poor permeability, respectively ${ }^{17}$. The basic criteria for selection of components of lipid formulation are; the lipophilicity of the drug, with solubility in pharmaceutically-acceptable lipid excipients which should be sufficient to allow the entire dose of the drug to be administered in a single dosage unit. 
Table: 1 Formulation components of S-SMEDDS ${ }^{11,15}$

\begin{tabular}{|c|c|c|c|c|c|}
\hline \multirow{3}{*}{$\frac{\text { s.no. }}{1}$} & \multirow{3}{*}{$\begin{array}{l}\text { Components } \\
\text { Oils }\end{array}$} & \multicolumn{4}{|l|}{ Examples } \\
\hline & & LCTs & MCTs & Fatty Acids & $\begin{array}{l}\text { Mono-/di- } \\
\text { glycerides }\end{array}$ \\
\hline & & $\begin{array}{l}\text { Olive oil } \\
\text { Corn oil } \\
\text { Soyabean oil } \\
\text { Castor oil }\end{array}$ & $\begin{array}{l}\text { Miglyol } 810 \\
\text { Miglyol } 812 \\
\text { Captex } 255 \\
\text { Captex } 300\end{array}$ & $\begin{array}{l}\text { Oleic acid } \\
\text { Palmitic acid }\end{array}$ & $\begin{array}{l}\text { Capmul MCM } \\
\text { Capmul GMO }\end{array}$ \\
\hline 2 & Surfactants & $\begin{array}{l}\text { Tweens } \\
\text { Spans } \\
\text { Cremophore RH40 } \\
\text { Labrafil 1944 CS } \\
\text { Labrafil M 2125 } \\
\text { Labrafac lipophile1349 WL } \\
\text { Labrasol } \\
\text { Lauroglycol } 90 \\
\text { Capryol } 90 \\
\text { Peceol }\end{array}$ & & & \\
\hline \multirow[t]{2}{*}{3} & \multirow[t]{2}{*}{$\begin{array}{l}\text { Cosurfactants } \\
\text { /Cosolvents }\end{array}$} & Alcohols \& polyols & Esters & $\begin{array}{l}\text { Esters of } \\
\text { propylene glycol }\end{array}$ & Amides \\
\hline & & $\begin{array}{l}\text { Ethanol } \\
\text { Isopropranol, butanol } \\
\text { benzyl alcohol } \\
\text { ethylene glycol } \\
\text { propylene glycol } \\
\text { butanediols } \\
\text { glycerol } \\
\text { pentaerythritol } \\
\text { sorbitol, mannitol } \\
\text { transcutol } \\
\text { dimethyl isosorbide } \\
\text { propylene glycol } \\
\text { HPMC }\end{array}$ & $\begin{array}{l}\text { ethyl propionate tributyl } \\
\text { citrate } \\
\text { acetyl triethyle citrate } \\
\text { acetyl tributyl citrate } \\
\text { ethylene oleate } \\
\text { ethyl caprylate } \\
\text { ethyl butyrate } \\
\text { triacetin } \\
\text { propylene glycol } \\
\text { monoacetate } \\
\text { propylene glycol diacetate } \\
\varepsilon \text {-caprolactone } \\
\delta \text {-valerolactone } \\
\beta \text {-butyrolactone }\end{array}$ & $\begin{array}{l}\text { Tetra hydrofuryl } \\
\text { alcohol } \\
\text { PEG ether } \\
\text { (glycofural) }\end{array}$ & $\begin{array}{l}\text { 2pyrrolidone } \\
\text { 2-piperidone } \\
\text { caprolactam } \\
\text { Nalkylpyrrolidone } \\
\text { N-alkylpiperidone } \\
\text { Nalkylcaprolactam } \\
\text { dimethylacetamide } \\
\text { polyvinyl } \\
\text { pyrrolidone }\end{array}$ \\
\hline 4 & $\begin{array}{l}\text { Consistency } \\
\text { builders }\end{array}$ & $\begin{array}{l}\text { Tragacanth } \\
\text { Cetyl alcohol } \\
\text { Stearic acid } \\
\text { Beeswax } \\
\end{array}$ & & & \\
\hline \multirow[t]{2}{*}{5} & \multirow[t]{2}{*}{$\begin{array}{l}\text { Enzyme } \\
\text { inhibitors }\end{array}$} & Non amino acids & Amino acids & Peptides & $\begin{array}{l}\text { Complexing } \\
\text { agents }\end{array}$ \\
\hline & & $\begin{array}{l}\text { P-amino benzamidine } \\
\text { FK-448 } \\
\text { Cosmostat mesylate } \\
\text { Sodium glycocolate }\end{array}$ & $\begin{array}{l}\text { aminoboronine derivatives } \\
\mathrm{n} \text {-acetylcysteine }\end{array}$ & $\begin{array}{l}\text { Bacitracin } \\
\text { Antipain } \\
\text { Leupeptin } \\
\text { Amastatin }\end{array}$ & $\begin{array}{l}\text { EDTA } \\
\text { EGTA } \\
\text { 1,10Phenanthroline } \\
\text { Hydroxychinoline }\end{array}$ \\
\hline 6 & $\begin{array}{l}\text { Adsorbents/ } \\
\text { solidifying } \\
\text { agents }\end{array}$ & $\begin{array}{l}\text { neusilin US2 } \\
\text { fujicalin } \\
\text { cellulose } \\
\text { lactose } \\
\text { silicates }\end{array}$ & & & \\
\hline
\end{tabular}

Table: 2 Biopharmaceutical classification of $\operatorname{drugs}{ }^{18}$

\begin{tabular}{|l|l|l|l|}
\hline BCS classes & Solubility & Permeability & Examples \\
\hline Class I & High & High & Metoprolol, diltiazem \\
\hline Class II & Low & High & Phenytoin, danazol \\
\hline Class III & High & Low & Cemetidine, neomycin \\
\hline Class IV & Low & Low & Taxol \\
\hline
\end{tabular}

- Since the aim of this study is to develop an oral formulation, therefore, solubility of drug in oils is more important as the ability of SMEDDS to maintain the drug in solubilized form is greatly influenced by the solubility of the drug in oil phase. Thus solubility of drug in various oils (Castor oil, Olive oil, Labrafil 1944 CS, Labrafac lipophil WL 1349, Capmul MCM C-10 etc) was determined $^{19}$. 
- Among physicochemical characteristics melting point and dose play a major role. Low melting point and low dose are desirable for development of lipidic systems. Drugs high melting point having with low $\log \mathrm{P}$ values (around 2) is not suitable for S-SMEDDS.

\section{Phase diagrams:}

Pseudo ternary phase diagram is used to map the optimal composition range for three key excipients according to the resulting droplet size following self emulsification, stability upon dilution and viscosity. Phase diagrams are useful tools to determine the number and types of phases, the wt $\%$ of each phase and the composition of each phase at a given temperature and composition of the system. These diagrams are three-dimensional but are illustrated in two-dimensions for ease of drawing and interpretation.

On the basis of the solubility study of drug, oil, surfactants, co-surfactants and aqueous phase were used for construction of phase diagram. Oil, surfactant, and co-surfactant are grouped in four different combinations for phase studies. Surfactant and co-surfactant (Smix) in each group were mixed in different weight ratio. These Smix ratios are chosen in increasing concentration of surfactant with respect to cosurfactant and in increasing concentration of co surfactant with respect to surfactant for detail study of the phase diagram for formulation of micro emulsion. For each phase diagram, oil, and specific Smix ratio are mixed thoroughly in different weight ratio in different glass vials. Different combination of oils and Smix were made so those maximum ratios were covered for the study to delineate the boundaries of phase precisely formed in the phase diagrams. Pseudo-ternary phase diagram was developed using aqueous titration method. Slow titration with aqueous phase is done to each weight ratio of oil and Smix and visual observation is carried out for transparent and easily flowable o/w micro emulsion. The physical state of the micro emulsion was marked on a pseudo-three-component phase diagram with one axis representing aqueous phase, the other representing oil and the third representing a mixture of surfactant and co-surfactant at fixed weight ratios (Smix ratio) ${ }^{20}$.

\section{Effect of drug on phase diagram}

The formulation amount of drug was added to the boundary formulations of the self microemulsifying domain of ternary phase diagrams. The self-micron-emulsifying performance was visually assessed after infinite dilution using purified water $^{19}$.

Mechanism of self-emulsification: Self emulsification occurs, when the entropy change occurs, dispersion is greater than the energy required to increase the energy required to increase the surface area of the dispersion ${ }^{21}$. The free energy of conventional emulsion formation is a direct function of the energy required to create a new surface between the two phases and can be described by the equation.

$$
\Delta \mathrm{G}=\sum \mathrm{N} \pi \mathrm{r}^{2} \sigma
$$

Where:

$\Delta \mathrm{G}$ is the free energy associated with the process (ignoring the free energy of mixing),

$\mathrm{N}$ is the number of droplets of radius $\mathrm{r}$,

$\sigma$ is interfacial energy with time
The two phases of the emulsion will tend to separate, in order to reduce the interfacial area and subsequently, the free energy of the system. Therefore, the emulsions resulting from aqueous dilution are stabilized by conventional emulsifying agents, which form a monolayer around the emulsion droplets and hence, reduce the interfacial energy, as well as providing a barrier to coalescence ${ }^{22}$. In case of self-emulsifying system, the free energy required to form the emulsion is either very low or positive or negative then, the emulsion process occurs spontaneously $^{23}$. Emulsification require very little input energy, involves destabilization through contraction of local interfacial regions. For emulsification to occur, it is necessary for the interfacial structure to have no resistance to surface shearing $^{24}$. In earlier work it was suggested that the case of emulsification could be associated with the ease by which water penetrates into the various liquid crystal or phases get formed on the surface of the droplet ${ }^{25}$. The addition of a binary mixture (oil/non-ionic surfactant) to the water results in the interface formation between the oil and aqueous continuous phases, followed by the solubilization of water within the oil phase owing to aqueous penetration through the interface, which occurs until the solubilization limit is reached close to the interface ${ }^{26}$. Further aqueous penetration will result in the formation of the dispersed liquid crystalline phase. As the aqueous penetration proceeds, eventually all materials close to the interface will be liquid crystal, the actual amount depending on the surfactant concentration in the binary mixture once formed, rapid penetration of water into the aqueous cores, aided by the gentle agitation of the self emulsification process causes interface disruption and droplet formation. A combination of particle size analysis and low frequency dielectric spectroscopy was used to examine selfemulsifying properties of a series of Imwitor 742 (a mixture of mono-and diglycerides of Caprylic acids/Tween 80) systems, which provided evidence that the formation of the emulsion may be associated with liquid crystal formation, although the relationship was clearly complex ${ }^{27}$. The presence of the drug may alter the emulsion characteristics, possibly by interacting with the liquid crystal phase.

\section{DESIGN OF S-SMEDDS FORMULATION}

A series of SMEDDS formulations were prepared using various oil, surfactant and cosurfactant . In all the formulations, the level of drug was kept constant. The amount of SMEDDS should be such that it should solubilize the drug (single dose) completely. The drug was added in the mixture. Then the components were mixed by gentle stirring and mixing, and heated at $37^{\circ} \mathrm{C}$. The mixture was stored at room temperature until used. So, prepared SMEDDS was the concentrate of oil, surfactant, co-surfactant and drug. Based upon the above results liquid SMEDDS is optimized which are further converted to Solid SMEDDS (Tablet) by adsorbing it on to adsorbent carriers like Neusilin US2, Fujicalin etc and various formulations were prepared ${ }^{19}$.

\section{SOLIDIFICATION TECHNIQUES FOR TRANSFORMING LIQUID/SEMISOLID SMEDDS TO S-SMEDDS}

\section{Capsule filling with liquid and semisolid self-emulsifying} formulations:

Capsule filling is the simplest and the most common technology for the encapsulation of liquid or semisolid SE formulations for the oral route. For semisolid formulations, it is a four-step process: (i) heating of the semisolid excipient to at least 200C above its melting point; (ii) incorporation of the 
active substances (with stirring); (iii) capsule filling with the molten mixture and (iv) cooling to room temperature. For liquid formulations, it involves a two-step process: filling of the formulation into the capsules followed by sealing of the body and cap of the capsule, either by banding or by microspray sealing ${ }^{28}$. In parallel with the advances in capsule technology proceeding, liquid-oros technology has been designed for controlled delivery of insoluble drug substances or peptides. This system is based on osmotic principles and is a liquid SME formulation system. It consists of an osmotic layer, which expands after coming into contact with water and pumps the drug formulation through an orifice in the hard or soft capsule ${ }^{29}$. A primary consideration in capsule filling is the compatibility of the excipients with the capsule shell. The advantages of capsule filling are simplicity of manufacturing; suitability for low-dose highly potent drugs and high drug loading (up to $50 \%(\mathrm{w} / \mathrm{w})$ ) potential.

\section{Spray drying:}

Essentially, this technique involves the preparation of a formulation by mixing lipids, surfactants, drug, solid carriers, and solubilization of the mixture before spray drying. The solubilized liquid formulation is then atomized into a spray of droplets. The droplets are introduced into a drying chamber, where the volatile phase (e.g. the water contained in an emulsion) evaporates, forming dry particles under controlled temperature and airflow conditions. Such particles can be further prepared into tablets or capsules. The atomizer, the temperature, the most suitable airflow pattern and the drying chamber design are selected according to the drying characteristics of the product and powder specification ${ }^{30}$.

\section{Adsorption to solid carriers:}

Free flowing powders may be obtained from liquid self microemulsifying formulations by adsorption to solid carriers. The adsorption process is simple and just involves addition of the liquid formulation onto carriers by mixing in a blender. The resulting powder may then be filled directly into capsules or, alternatively, mixed with suitable excipients before compression into tablets. A significant benefit of the adsorption technique is good content uniformity. For an instance a formulation of Liquid SMEDDS was made which is converted to Solid SMEDDS using Malto dextrin as a solid carrier. SMEDDS can be adsorbed at high levels (up to $70 \%$ $(w / w))$ onto suitable carriers ${ }^{31}$. Solid carriers can be micro porous inorganic substances, high surface-area colloidal inorganic adsorbent substances, cross-linked Polymers or Nanoparticle adsorbents, for example, silica, silicates, magnesium trisilicate, magnesium hydroxide, talcum crospovidone, cross-linked sodium carboxymethyl cellulose and cross linked polymethyl methacrylate. Cross-linked polymers create a favorable environment to sustain drug dissolution and also assist in slowing down drug reprecipitation. Nanoparticle adsorbents comprise porous silicon dioxide (Sylysia 550), carbon nanotubes, carbon nanohorns, fullerene, charcoal and bamboo charcoal ${ }^{32}$.

\section{Melt granulation:}

Melt granulation is a process in which powder agglomeration is obtained through the addition of a binder that melts or softens at relatively low temperatures. As a 'one-step' operation, melt granulation offers several advantages compared with conventional wet granulation, since the liquid addition and the subsequent drying phase are omitted. Moreover, it is also a good alternative to the use of solvent.
The main parameters that control the granulation process are impeller speed, mixing time, binder particle size, and the viscosity of the binder. A wide range of solid and semisolid lipids can be applied as meltable binders. Thereinto, Gelucire1, a family of vehicles derived from the mixtures of mono-/di-/tri-glycerides and polyethylene glycols (PEG) esters of fatty acids, is able to further increase the dissolution rate compared with PEG usually used before, probably owing to its SME property ${ }^{33}$. Other lipid-based excipients evaluated for melt granulation to create solid SMES include lecithin, partial glycerides, or polysorbates. The melt granulation process was usually used for adsorbing SMES (lipids, surfactants, and drugs) onto solid neutral carriers (mainly silica and magnesium alumina meta silicate) ${ }^{34,35}$.

\section{Melt extrusion/extrusion Spheronization:}

Melt extrusion is a solvent-free process that allows high drug loading $(60 \%)$, as well as content uniformity. Extrusion is a procedure of converting a raw material with plastic properties into a product of uniform shape and density, by forcing it through a die under controlled temperature, product flow, and pressure conditions ${ }^{36}$. The size of the extruder aperture will determine the approximate size of the resulting spheroids. The extrusion-spheronization process is commonly used in the pharmaceutical industry to make uniformly sized spheroids (pellets). The extrusion spheronization process requires the following steps: Dry mixing of the active ingredients and excipients to achieve a homogeneous powder; wet massing with binder; extrusion into a spaghetti-like extrudate; spheronization from the extrudate to spheroids of uniform size; drying; sifting to achieve the desired size distribution and coating (optional). In the wet masses comprising SMES (Polysorbate 80 and mono-/di-glycerides), lactose, water and MCC, the relative quantities of SMES and water had a significant effect on the extrusion force, size spread, disintegration time, and surface roughness of pellets. Studies suggested that the maximum quantity of this SMES that can be solidified by extrusion spheronization occupies $42 \%$ of the dry pellet weight ${ }^{37}$. Generally, the higher the water level, the longer the disintegration time ${ }^{37}$. The rheological properties of wet masses may be measured by an extrusion capillary. It has been shown that SMES containing wet mass with a wide range of rheological characteristics can be processed, but a single rheological parameter cannot be used to provide complete characterization of how well it can be processed by extrusionspheronization ${ }^{38}$. Applying extrusion-spheronization, SME pellets of diazepam and progesterone and bi-layered cohesive SME pellets have been prepared ${ }^{39,40}$

\section{Dosage form development of S-SMEDDS:}

Self-emulsifying capsules: After administration of capsules containing conventional liquid SE formulations, micro emulsion droplets form and subsequently disperse in the GI tract to reach sites of absorption. However, if irreversible phase separation of the micro emulsion occurs, an improvement of drug absorption cannot be expected. For handling this problem, sodium dodecyl sulfate was added into the SE formulation ${ }^{41}$. With the similar purpose, the super saturable SMEDDS was designed, using a small quantity of hydroxyl propyl methyl cellulose (or other polymers) in the formulation to prevent precipitation of the drug by generating and maintaining a supersaturated state in vivo. This system contains a reduced amount of a surfactant, thereby minimizing GI side effect ${ }^{42,43}$. 
Self-emulsifying suppositories: Kim and $\mathrm{Ku}$ (2000) investigated the Solid-SEDDS could increase not only GI adsorption but also rectal/vaginal adsorption. Glycyrrhizin which by the oral route, barely achieves therapeutic plasma concentrations, can obtain satisfactory therapeutic levels for chronic hepatic diseases by either vaginal or rectal SE suppositories. The formulation included glycyrrhizin and a mixture of a C6-C18 fatty acid glycerol ester and a C6C18 fatty acid macrogol ester ${ }^{44,45}$.

Self-emulsifying nanoparticles: Nanoparticle techniques have been useful in the production of SE nanoparticles. Solvent injection is one of these techniques. In this method, the lipid, surfactant and drugs were melted together and injected drop wise into a stirred non-solvent. The resulting SE nanoparticles were thereafter filtered out and dried. This approach yielded nanoparticles (about $100 \mathrm{~nm}$ ) with a high drug loading efficiency of $74 \%{ }^{46}$. More recently, a novel nanoparticle drug delivery system consisting of chitosan and Glyceryl Monooleate (GMO) for the delivery of Paclitaxel (PTX) has been developed. The SE property of GMO enhanced the solubility of PTX and provided a foundation for chitosan aggregation, meanwhile causing near $100 \%$ loading and entrapment efficiencies of PTX ${ }^{47}$.

\section{REFERENCES}

1. Balakrishnan P, Lee B J, Oh D H, Kim J O, Lee Y I, Kim D D, Jee J P, Lee Y B, Woo J S, Yon C S, Choi H G, Enhanced oral bioavailability of Coenzyme Q10 by self-emulsifying drug delivery systems, Int J Pharm 2009, 374, 66-72.

2. Cui S X, Nie S F, Li L, Wang C G, Sun J P, Preparation and evaluation of self-microemulsifying drug delivery system containing vinpocetine, Drug Dev In Pharm, 2009, 35, 603-611.

3. Woo J S, Song Y K, Hong J Y, Lim S J, Kim C K, Reduced foodeffect and enhanced bioavailability of a self-microemulsifying formulation of itraconazole in healthy volunteers, Eur J Pharm Sci, 2008, 33, 159-165.

4. Nazzal S, Smalyukh I I, Lavrentovich O D, Khan M A, Preparation and in vitro characterization of a eutectic based semisolid selfnanoemulsified drug delivery system (SMEDDS) of ubiquinone: mechanism and progress of emulsion formation, Int J Pharm, 2002, 235, 247-265.

5. Chen Y, Li G, Wu X, Chen Z, Hang J, Qin B, Chen S, Wang R, Selfmicroemulsifying drug delivery system (SMEDDS) of vinpocetine: formulation development and in vivo assessment, Biol Pharm Bull, 2008, 31, 118-125.

6. Nazzal S, Khan M, Controlled release of a self-emulsifying formulation from a tablet dosage form: stability assessment and optimization of some processing parameters, Int J Pharm, 2006, 315, $110-121$.

7. Wang L, Dong J, Chen J, Eastoe J, Li X, Design and optimization of a new self-nanoemulsifying drug delivery system, $\mathrm{J}$ of Colloid Interface Sci, 2009, 330, 443-448.

8. Tang B, Cheng G, Gu J C, Xu C H, Development of solid selfemulsifying drug delivery systems: preparation techniques and dosage forms, Drug Discovery Today, 2008, 13, 606-612.

9. Rao S V R, Shao J, Self-nanoemulsifying drug delivery systems (SNEDDS) for oral delivery of protein drugs: I. Formulation development, Int J Pharm, 2008, 362, 2-9.

10. Attama A A, Mpamaugo V E, Pharmacodynamics of piroxicam from self-emulsifying lipospheres formulated with homolipids extracted from Capra hircus, Drug Deliv 2006, 13, 133-137.

11. Shinde G, S Kuchekar, P Kamble, A Kuchekar, K R shirsagar, B Kuchekar, Self microemulsifying drug delivery system: A novel approach for hydrophobic drugs, Int J Pharm Sci, 2011, 3, 988-1005.

12. Preethi Sudheer, Nishanth Kumar M, Satish Puttachari, Uma Shankar M S, Thakur R S, Approaches to development of solid- self micron emulsifying drug delivery system: formulation techniques and dosage forms - a review, Asian Journal of Pharmacy and Life Science, 2012, 2(2), 214-225.
Self-emulsifying sustained/controlled-release pellets: Pellets, as a multiple unit dosage form, possess many advantages over conventional solid dosage forms, such as flexibility of manufacture, reducing intrasubject and intersubject variability of plasma profiles and minimizing GI irritation without lowering drug bioavailability ${ }^{48}$. Thus, it is very appealing to combine the advantages of pellets with those of SMEDDS by self micron-emulsifying pellets.

\section{CONCLUSION}

S-SMEDDS are a promising approach for the formulation of drugs with poor aqueous solubility. The oral delivery of lipophilic drugs can be made possible by S-SMEDDS, which have been shown to substantially improve oral bioavailability. As mentioned above, numerous studies have confirmed that SSMEDDS substantially improved solubility/dissolution, absorption and bioavailability of poorly water-soluble drugs. As improvements or alternatives of conventional liquid SMEDDS, S-SMEDDS are superior in reducing production cost, simplifying industrial manufacture, and improving stability as well as patient compliance. Most importantly, SSMEDDS are very flexible to develop various solid dosage forms for oral and parenteral administration. Moreover, GI irritation is avoidable and controlled/sustained release of drug is achievable.

13. Anand U, Kyatanwar, Solid-Self micro-emulsifying drug delivery system (SMEDDS): Review, J of Phar Res, 2010, 3, 75-83.

14. Serajuddin et al, Formulation development strategies for solid microemulsion preconcentrate ( solid SEDDS/ SMEDDS), J Pharm Sci, 2009, 98, 1750-1764.

15. Barkat Ali Khan, Satar Bakhsh, Haroon Khan, Tariq Mahmood, Akhtar Rasul, Basics of Self Micro Emulsifying Drug Delivery System, Journal of Pharmacy and Alternative Medicine, 2012, 1, 1319.

16. O'Driscoll C M, B T Griffin, Biopharmaceutical challenges associated with drugs with low aqueous solubility- the potential impact of lipid-based formulations, Adv Drug Deliv Rev, 2008, 60, 617-624.

17. Tapas A R, P S Kawtikwar, D M Sakarkar, Modification of felodipine properties using spherically agglomerated solid dispersions, Am J Drug Discovery Dev, 2011, 1, 160-173.

18. Vikash Dash, Asha Kesari, Role of Biopharmaceutical Classification System in drug development program, Journal of Current Pharmaceutical Research, 2011, 5(1), 28-31.

19. Chirag Raval, Neha Joshi, Jitendra patel, U M Upadhyay, Enhanced oral bioavailability of olmesartan by using novel solid self emulsifying drug delivery system, International journal of advanced pharmaceutics, 2012, 2(2), 82-92.

20. Sheikh S, Shakeel F, Talegaonkar S, Ahmad F J, Khar R K, Ali M, Development and bioavailability assessment of ramipril nanoemulsion formulation, Eur J Pharm Biopharm, 2007, 66, 227 243.

21. Pouton $\mathrm{C} \mathrm{W}$, Effects of the inclusion of a model drug on the performance of self-emulsifying formulations, J Pharma Pharmacol, 1985, 37,1P.

22. Reiss H, Entropy induced dispersion of bulk liquids, J Colloids Interface Science, 1975, 53, 61-70.

23. Craig D Q M, Lievens H S R, Pitt KG, Storey D E, An investigation into the physico-chemical properties of self-emulsifying systems using low frequency dielectric spectroscopy, surface tension measurements and article size analysis, Int J Pharm, 1993, 96, 147155 .

24. Dabros T, Yeung A, Masliyah J, Czarnecki J, Emulsification through area contraction, J. Colloids, interface science, 1999, 210, 222-224.

25. Wakerly M G, C W Pouton, B J Meakin, F S Morton, Selfemulsification of veg: oil-non-ionic surfactant mixtures, ACS symp Ser, 1986, 311, 242-255. 
26. Wakerly M G, Pouton C W, Maekin B J, Evaluation of the selfemulsifying performance of a non-ionic surfactant-vegetable oil mixture, J Pharma Pharmacol, 1987, 39, 6P.

27. Craig DQM, Lievens HSR, Pitt KG, Storey DE, An investigation into the physico-chemical properties of self-emulsifying systems using low frequency dielectric spectroscopy, surface tension measurements and article size analysis, Int J Pharm, 1993, 96, 147-155.

28. Jannin V, Musakhanian J, Marchaud D, Approaches for the development of solid and semi-solid lipid-based formulations, Adv Drug Deliv Rev, 2008, 60, 734-746.

29. Dong L et al, A novel osmotic delivery system, L-OROS SOFTCAP, Proceedings of the International Symposium on Controlled Release of Bioactive Materials, 2000, July, Paris (CD ROM).

30. Tao Yi, Jiangling Wan, Huibi Xu, Xiangliang Yang, A new solid self-microemulsifying formulation prepared by spray-drying to improve the oral bioavailability of poorly water soluble drugs, European Journal of Pharmaceutics and Biopharmaceutics, 2008, 70, 439-444.

31. Ito $\mathrm{Y}$, Kusawake $\mathrm{T}$, Ishida $\mathrm{M}$, Oral solid gentamicin preparation using emulsifier and adsorbent, J Control Release, 2005, 105, 23-31.

32. Venkatesan N, Yoshimitsu J, Ito Y, Shibata N, Takada K, Liquid filled nanoparticles as a drug delivery tool for protein therapeutics. Biomaterials 2005, 26, 7154-7163.

33. Seo A, Holm P, Kristensen H.G, Schæfer T, The preparation of agglomerates containing solid dispersions of diazepam by melt agglomeration in a high shear mixer, Int J Pharm, 2003, 259, 161 171.

34. Gupta M K, Goldman D, Bogner R H, Tseng Y C, Enhanced drug dissolution and bulk properties of solid dispersions granulated with a surface adsorbent, Pharm Dev Technol. 2001, 6, 563-572.

35. Gupta M K, Tseng Y C, Goldman D, Bogner R H, Hydrogen bonding with adsorbent during storage governs drug dissolution from solid dispersion granules, Pharm Res, 2002, 19, 1663-1672.

36. Verreck G, Brewster M E, Melt extrusion-based dosage forms, excipients and processing conditions for pharmaceutical formulations, Bull Tech Gattefosse, 2004, 97, 85-95.

37. Newton M, Petersson J, Podczeck F, Clarke A, Booth S, The influence of formulation variables on the properties of pellets containing a selfemulsifying mixture, J Pharm Sci, 2001, 90, 987995.
38. Newton $\mathbf{J} \mathbf{M}$ et al, Formulation variables on pellets containing selfemulsifying systems, Pharm Tech Eur, 2005, 17, 29-33.

39. Tuleu C, Newton M, Rose J, Euler D, Saklatvala R, Clarke A, Comparative bioavailability study in dogs of a self-emulsifying formulation of progesterone presented in a pellet and liquid form compared with an aqueous suspension of progesterone, J Pharm Sci, 2004, 93, 1495-1502.

40. Iosio $\mathrm{T}$ et al, Bi-layered self-emulsifying pellets prepared by coextrusion and spheronization: influence of formulation variables and preliminary study on the in vivo absorption, Eur J Pharm Biopharm, 2008, 69(2), 686-697.

41. Itoh $\mathrm{K}, \mathrm{Y}$ Tozuka, $\mathrm{T}$ Oguchi, $\mathrm{K}$ Yamamoto, Improvement of physicochemical properties of N-4472 part I formulation design by using self-microemulsifying system, Int J Pharm, 2002, 238, 153-160.

42. Gao P, W Morozowich, Development of supersaturable self emulsifying drug delivery system formulations for improving the oral absorption of poorly soluble drugs, Expert Opin Drug Discov, 2006, 3, 97-110.

43. Gao P, B D Rush, W P fund, T Huang, J M Bauer, Development of a supersaturable SEDDS (S-SEDDS) formulation of paclitaxel with improved oral bioavailability, J Pharm Sci, 2003, 92, 2386-2398.

44. Takada K, M Murakami, Glycyrrhizin preparations for transmucosal absorption, 2005, US Pat 6890547, http://www.findthatpatent.com/Glycyrrhizin_preparations_for_transm ucosal_absorption,6890547.html

45. Wanwimolruk S, H Zhang, P C Coville, D J Saville, L S Davis, In vitro hepatic metabolism of CYP3A-mediated drug, quinine in the Antarctic Adelie penguins, Compar Biochem Physiol, 1999, 124C, 301-307.

46. Attama A A, M O Nkemnele, In vitro evaluation of drug release from self micro-emulsifying drug delivery systems using a novel biodegradable homolipid from Capra hircus, Int J Pharm 2005, 304, 4-10.

47. Trickler W J A, Novel nanoparticle formulation for sustained paclitaxel Delivery, AAPS Pharm, Sci, Technol, 2008, 9, 486-493.

48. Gandhi R, C Lal Kaul, R Panchagnula, Extrusion and spheronization in the development of oral controlled-release dosage forms, PSTT 2, 1999, 160-170. 